\title{
Canine vector-borne diseases in India: a review of the literature and identification of existing knowledge gaps
}

\author{
Puteri Azaziah Megat Abd Rani*1, Peter J Irwin², Mukulesh Gatne³, Glen T Coleman¹ and Rebecca J Traub1
}

\begin{abstract}
Despite the combination of favourable climate for parasites and vectors, and large populations of stray dogs, information concerning the epidemiology, diagnosis and management of canine vector-borne diseases in India is limited. However, with the country's expanding economy and adaptation to western culture, higher expectations and demands are being placed on veterinary surgeons for improved knowledge of diseases and control. This review aims to provide an overview of the current state of knowledge of these diseases in India and identify existing knowledge gaps in the literature which need to be addressed. The available literature on this subject, although limited, suggests that a number of canine vector-borne diseases such as filariasis, babesiosis and ehrlichiosis are endemic throughout India, as diagnosed mostly by morphological methods. Detailed investigations of the epidemiology and zoonotic potential of these pathogens has been neglected. Further study is essential to develop a better understanding of the diversity of canine vector-borne diseases in India, and their significance for veterinary and public health.
\end{abstract}

\section{Review}

India has a wide range of climatic zones, from montane (cold, wet alpine) and semi-arid regions to the wet tropics, which make it suitable for a diverse range of vectors and pathogens of medical and veterinary importance, whose transmission and geographical distribution are closely linked to regional temperature, rainfall and humidity [1]. Knowledge of parasitic diseases of companion animals in India remains incomplete, particularly outside the subcontinent, despite climatic conditions that are often conducive for the transmission of enteric and vector-borne parasitic infections.

India's dog population is estimated at 25 million and can be divided into four categories which can be defined as follows: pets (restricted and supervised); family dogs (partially restricted, wholly dependent); community dogs (unrestricted, partially dependent); and feral dogs (unrestricted, independent) [2]. Approximately $80 \%$ of the population fall into the latter three categories leaving over 5 million dogs within the 'pet' category. In a recent survey, $17 \%$ of households in India were reported to own a pet/

* Correspondence: puteri.megatabdrani@uqconnect.edu.au

1 School of Veterinary Science, The University of Queensland, Queensland 4072, Australia

Full list of author information is available at the end of the article domesticated dog [3]. Despite this, information available to veterinarians concerning the prevalence, epidemiology, diagnosis and management of canine vector-borne diseases (CVBD) and those of zoonotic concern is scarce [4]. This is not entirely unexpected in a country such as India where agriculture is the means of livelihood for about two-thirds of the work force and competency in animal husbandry/production animal medicine are rightfully emphasised in university veterinary curricula to meet the demands of India's agricultural/rural community. However, with one of the fastest growing economies in the world, India's increasingly affluent middle class is becoming increasingly accustomed to Western culture. This has resulted in changing attitudes towards companion animal ownership, with higher expectations and demands being placed on veterinary surgeons and the companion animal industry for improved knowledge of veterinary diseases and products for treatment and control $[4,5]$.

The purpose of this paper is to present a summary of the extant literature pertaining to CVBD in India and to provide an overview of the current state of knowledge of these diseases. In order to achieve this, a detailed review was undertaken of the available literature within Indian 
veterinary and animal science journals, many of which are not indexed in the internationally-accessible scientific search engines.

\section{Filarial nematodes of dogs}

The filarial nematodes are characterized by their tissue tropism and their dependence upon blood-feeding arthropod vectors for transmission [6]. The most commonly reported species in dogs are; Dirofilaria immitis, Dirofilaria repens, Acanthocheilonema reconditum, Acanthocheilonema dracunculoides, Brugia malayi, Brugia ceylonesis and Brugia pahangi [7-9]. Dirofilaria immitis is responsible for heartworm disease in dogs, yet microfilaraemia associated with other filarial infections is commonly detected in blood films of dogs in tropical countries, which theoretically necessitates specific identification of the filarial parasite in order to exclude the nonpathogenic species. This requires experienced personnel and it may be difficult to detect multiple infections with more than one species of filarial worm [10]. Despite the availability of published measurements of various microfilariae, the inaccuracy of morphological diagnosis was demonstrated by Rishniw and colleagues (2006) [8] when microfilariae initially identified as $A$. reconditum were later characterised as $D$. immitis by molecular methods. Both D. repens and Acanthocheilonema spp. develop into adult worms in the subcutaneous tissue resulting in skin nodules. Adults of Brugia spp. are usually recovered from the mandibular, retropharyngeal or axillary lymphatics. Most infections with D. repens, Acanthocheilonema spp. and Brugia spp. are of minimal veterinary clinical significance, however all canine filariae have the potential to infect humans and remain significant from a public health perspective.

Dirofilaria immitis infection in humans is very rare and usually associated with pulmonary lesions or radiological coin lesions of the lung. The significance of $D$. immitis infection is the potential for a radiological misdiagnosis of primary or metastatic lung tumour, leading to thoracotomy for open lung biopsy or wedge resection of the lung to obtain the correct diagnosis $[11,12]$. Sporadic cases of immature heartworms in unusual locations in the human body such as the eye [13], mesentery [14], cerebral artery [15], spermatic cord [16] and liver [17] have also been reported. Dirofilaria repens is a parasite of the subcutaneous tissue in dogs that can also accidentally infect humans, causing a condition referred to as subcutaneous dirofilariasis. It is considered to be a re-emerging zoonosis, transmitted by mosquitoes, endemic to Southern and Eastern Europe and Asia, particularly Sri Lanka [18], Malaysia [19] and India [20]. The distribution of human cases of subcutaneous dirofilariasis appears to mirror the distribution of canine cases [18,20]. Several genera of mosquitoes are competent vectors for $D$. immitis and $D$. repens, including Culex, Aedes and Anopheles [9,21]. Acanthocheilonema reconditum and $A$. dracunculoides rarely cause significant illness in dogs. Their importance lies in the fact that their microfilariae can be easily confused with those of $D$. immitis and $D$. repens. The adults from these species can be found in the body cavity and subcutaneous tissues of dogs. They are prevalent in the United States, Italy [22], Egypt [23] and Africa [24]. The intermediate host for $A$. reconditum are Ctenocephalides (flea) and Heterodoxus (lice) [25], and a biting fly, Hippobosca longipennis acts as intermediate host for $A$. dracunculoides [26].

Dirofilaria spp., Acanthocheilonema spp. and Brugia spp., have all been reported in India [27-29]. During one recent survey, post-mortem examination of 240 indigenous dogs at a local slaughterhouse (for dogs) in northeast India revealed $34 \%$ of dogs harboured heartworm infection [30]. The authors noted that among the heartworm-positive dogs, 35\% had non-patent infections and none of the animals demonstrated overt clinical signs of disease on brief ante-mortem inspection. Both $D$. immitis and $D$. repens were isolated at post-mortem examination from $57 \%(4 / 7)$ and $14 \%(1 / 7)$ of dogs respectively in the central Indian state of Orissa [31]. Two recent surveys of microfilaraemic dogs in Kerala [20] and Karnataka States [28] in southern India, found only D. repens at a prevalence of $7 \%(n=160)$ and $21 \%(n=400)$ respectively. It is important to note however that these latter studies on Dirofilaria utilized morphological methods for diagnosis, which can be potentially misleading as microfilarial dimensions of both species of Dirofilaria often overlap. Moreover, it may be difficult to detect multiple infections with more than one species of filarial worm. Although minimally pathogenic in dogs, D. repens is zoonotic and a number of human cases of subcutaneous dirofilariasis in the medical literature of India have been reported in the same region [20]. Despite the limited number of surveys performed, veterinarians in India strongly believe that heartworm is confined to the northeast and D. repens to southern India. This assumption is debatable since competent mosquito vectors for $D$. immitis are present throughout central and southern India. For example, Aedes albopictus [32-34], a competent vector for $D$. immitis is present in Maharastra, Karnataka and Pondicherry [35], and heartworm is yet to be reported in dogs from these areas. Moreover, the tropical climate of these regions have average temperature ranges from $20^{\circ} \mathrm{C}$ in winter to $37^{\circ} \mathrm{C}$ in summer [36] and this provides a suitable environment for $D$. immitis development within the vector [37-39]. It is known that the development of $D$. immitis can also vary within mosquito species $[40,41]$ and the genetic diversity of different strains of the same species could therefore be accountable for the variation observed. A case of human pulmonary dirofilariasis due 
to D. immitis however, was reported in Mumbai in 1989, adding further doubt to its currently accepted geographical distribution [42]. Studies into the effect of temperature on larval development of Dirofilaria have largely focused on D. immitis with less information available on D. repens [43].

At present, 1.3 billion people worldwide are at risk of lymphatic filariasis and about 120 million people in 83 countries are affected. Amongst them, 45.5 million live on the Indian subcontinent [44]. Brugia malayi is responsible for $10 \%$ of cases of zoonotic lymphatic filariasis in humans and is restricted to the tropics [45]. Although the main reservoirs are populations of leaf-eating monkeys (Presbytis spp.) [46], this filarial nematode has also been found to infect cats in Malaysia [47] and Thailand [48]. Mansonia, Aedes, Culex and Armigeres are four genera of mosquitoes that are able to transmit brugian filariosis [49]. In people, the disease may range from causing few clinical symptoms, or sufferers may experience acute manifestations such as fever, rashes, orchitis, lymphadenitis and lymphagitis that, if progressing to chronic infection, will lead to lymphoedema or 'elephantiasis' [6]. Another species, Brugia pahangi, has not been recognized in natural infections in humans but is able to infect humans experimentally [50]. Brugia pahangi was found mixed with other filariid species in $54.7 \%$ of dogs $(n=68)$ in Malaysia [51] and was isolated from $7.6 \%(n=52)$ of cats in Thailand [52].

Brugia ceylonensis was first described from the lymphatics of dogs in Sri Lanka in 1962 [53]. In a Sri Lankan survey of 65 dogs, $44.6 \%$ were positive for microfilaria; of these, $62 \%$ and $7 \%$ had single infections with $D$. repens and B. ceylonensis respectively, while $31 \%$ had mixed infections with both species [54]. An adult B. ceylonensis was recently isolated from the conjunctiva of a person in Sri Lanka [55] raising public health concerns about the zoonotic potential of this canine filaria.

Brugian filariasis accounts for approximately 5\% of lymphatic filariasis cases in India where over 40 million people are estimated to be infected [56]. Recently, based on immunodiagnostic testing, 16/75 (21.3\%) microfilaraemic dogs were shown to harbour $B$. malayi [57]. The role of dogs (and cats) as reservoirs of brugian filariasis has important implications for parasite control strategies. If canine and feline reservoir hosts exist in these areas, a more inter-sectorial approach to control may be required in addition to the traditional use of mass drug administration programs advocated by the World Health Organization. The species of Brugia recovered from dogs in Kerala therefore requires confirmation using molecular diagnostic tools, as it is possible that the immunodiagnostic tests utilized to diagnose infection in dogs crossreact with other Brugia spp. [58].

\section{Canine tick-borne diseases}

Babesiosis is an important disease of domestic and wild Canidae, caused by intraerythrocytic piroplasms of the genus Babesia and, potentially, Theileria. Historically, canine babesiosis has been attributed to infection with either Babesia canis or Babesia gibsoni. A wide range of clinical signs is reported for babesiosis, with the greatest severity in younger dogs, which may present to the veterinarian in a state of shock [59]. Lethargy is the most common symptom, followed by anorexia, pale mucous membranes, vomiting, amber to brown urine, splenomegaly, jaundice, weight loss, tachycardia and tachypnea.

Based on genetic data, vector specificity and variation of pathogenicity, three species of large Babesia have been identified. It is diagnostically important to differentiate between $B$. canis, B. vogeli and B. rossi $[60,61]$ since the virulence, prognosis and response to treatment differ for each organism. Babesia vogeli is found worldwide and considered to be mildly virulent [62]. It usually results in transient haemolytic anaemia with a regenerative response (reticulocytosis) or a subclinical infection. Babesia canis, found in Europe, is considered to be virulent in dogs while $B$. rossi, reported only in Africa, is highly virulent, often causing peracute disease, resulting in hypoxia, hypotensive shock and disseminated intravascular coagulation and death before anaemia can develop [63]. Babesia gibsoni (Asian genotype), B. conradae (previously Californian genotype) and the $B$. microti-like species (also referred to as the Spanish isolate or Theileria annae) are each smaller piroplasm species that cause progressive haemolytic anaemia; $B$. conradae may produce the highest level of parasitaemia with more pronounced anaemia, higher fatality rates and be more likely to become recrudescent following treatment than B. gibsoni [64]. Babesia spp. are transmitted to dogs by a wide variety of ixodid ticks including Haemaphysalis longicornis, H. leachi, Rhipicephalus sanguineus and Dermacentor marginatus [65], although infection from blood transfusions [66], transplacental transmission [67], and direct transmissions through bite wounds [68] have been reported. Furthermore, subclinical infections by milder strains may simply remain dormant in a state of premunity, until such time as the animal is immunocompromised by unrelated disease or by iatrogenic drug administration.

The situation regarding canine babesiosis in India is far from clear. Only $0.1 \%$ of dogs $(n=5,832)$ in Chennai were found positive for Babesia gibsoni [69] microscopically. Other studies found $9 \%$ and $22 \%$ of dogs in Uttar Pradesh [70] and Assam [71] to be infected with Babesia spp., respectively, however it is unclear which genotypes of Babesia were harboured by these dogs. The pathogenicity of Babesia is known to vary in different regions of India and this may be due to variations in the species and 
strains present. It is likely that both $B$. vogeli and B. gibsoni are co-endemic in India and the ticks Rhipicephalus sanguineus and Haemaphysalis longicornis are the putative vectors, respectively.

Ehrlichia is an alpha-proteobacteria belonging to the family Ehrlichiaceae. In dogs, species that are able to produce infection are E. canis (tropical canine pancytopaenia), E. ewingii (canine granulocytic ehrlichiosis), and $E$. chaffeensis (Human monocytic ehrlichiosis) [10,72]. The one that most commonly affects dogs and causes the most severe clinical signs is Ehrlichia canis. The prevalence of E. canis is dependent on the distribution of the vector, Rhipicephalus sanguineus tick, which is widespread across tropical and subtropical regions [65].

A handful of studies investigating the prevalence of canine ehrlichiosis in India using conventional examination of stained blood smears have reported prevalences between $0.35 \%$ in Punjab [73] and 18.9\% in Nagpur [74]. To date, only one study reported using a species-specific nested PCR and found 46/98 (50\%) privately owned dogs in Chennai positive for E. canis compared to $19 \%$ by microscopy [75]. However, amplicons were not subjected to DNA sequencing to confirm results and information with regards to the clinical status of these dogs was not reported. It is unknown if other species of Ehrlichia or Anaplasma of veterinary or public health significance are present.

Canine hepatozoonosis is a systemic infection caused by the protozoan Hepatozoon canis. It is transmitted by ingestion of an infected dog tick, R. sanguineus, rather than tick bites [76]. The distribution of $H$. canis reflects the geographical distribution of its vector, which is present in Africa, southern Europe, Asia, Australia and the Americas [65]. The clinical spectrum of $H$. canis infection ranges from subclinical to severe, life-threatening disease [77]. Hepatozoon canis mainly infects the haemolymphatic tissue and blood cell-forming organs including the bone marrow, lymph nodes and spleen. Dogs with severe clinical disease show signs such as fever, inappetence, weight loss, anaemia, hyperglobulinaemia often resulting in hepatitis, pneumonia and glomerulonephritis associated with $H$. canis meronts. Co-infection of $H$. canis with other infectious agents such as Ehrlichia, Leishmania and parvovirus is common [78-80]. Immune suppression induced by an infectious agent or chemotherapy may reactivate pre-existing infections [79].

Canine hepatozoonosis has been reported in dogs in Mumbai associated with clinical signs of anaemia, thrombocytopenia, hepatitis, hyperglobulinaemia and elevate blood urea and nitrogen [81]. Information with regard to the immune status of these dogs and co-infection with other vector-borne diseases was not described. In most cases however, subclinical infections occurs with a prevalence ranging from $3-9 \%[82,83]$.

\section{Canine Leishmania and Trypanosoma}

Canine leishmaniasis is caused by protozoa belonging to the genus Leishmania. Among the Leishmania species known to infect humans worldwide, only Leishmania tropica and Leishmania donovani are presumed to be anthroponotic [84-86]. There are two forms of leishmaniasis, cutaneous and visceral. Cutaneous leishmaniasis is associated with members of Leishmania aethiopica, $L$. major, L. tropica, L. mexicana and L. braziliensis while visceral leishmaniasis is caused by $L$. donovani, and $L$. infantum [63]. Dogs are considered to be the major reservoir for the visceral form of human disease [87]. Sand flies of the genus Phlebotomus and Lutzomyia are the primary vectors responsible for disease transmission; the infected female sand fly inoculates a vertebrate host with flagellated promastigotes during a blood meal [63]. Leishmaniasis is a slowly progressive disease that can take up to 7 years to become clinically apparent in dogs. However, for reasons that are not well understood, many dogs appear naturally resistant to this parasite and may remain asymptomatic [87]. It is estimated that only $10 \%$ of dogs residing in endemic areas actually develop clinical disease [63] with the majority acting as subclinical carriers. Furthermore, up to $20 \%$ of infected dogs may mount an adequate immune response and spontaneously recover from clinical illness [88]. Cutaneous lesions are present in up to $89 \%$ of infected dogs, with or without overt signs of visceral involvement [87]. However, it should be noted that any animal presenting with apparent lesions should be presumed to have disseminated leishmaniasis because involvement of the integument often occurs late in disease progression [87]. One of the most consistent findings among dogs infected with Leishmania spp. is the presence of hyperproteinaemia due to hyperglobulinaemia, often in conjunction with hypoalbuminaemia, while deposition of immune complexes into joints and kidneys results in polyarthritis and glomerulonephritis respectively [87].

Both species of Leishmania considered to be anthroponotic are present in India; $L$. donovani the cause of 'kala azar' and L. tropica, the cause of cutaneous leishmaniasis. Although sporadic case reports of cutaneous leishmaniasis in dogs from Rajasthan do exist [89], the dog's role as a zoonotic reservoir for these Leishmania species has remained largely unexplored. A report of cutaneous leishmaniasis in Rajasthan highlighted the presence of clinical cases in dogs corresponds to the area with human cutaneous leishmaniasis, with $24 \%$ (6/25) pet dogs, $21 \%$ (17/79) stray dogs and 68.04\% (64/95) humans positive for amastigotes (presumably L. tropica) from skin lesion smears [90]. Recently, 161 cases of localized cutaneous leishmaniasis were reported in humans from 2001-2003 in the northern state of Himachal Pradesh [91]. Molecular characterization of 10 isolates from humans in this 
sub-alpine region revealed a unique strain of $L$. donovani in 8 and $L$. tropica in 2 out of the ten patients. The vector and potential reservoir hosts for this novel strain of $L$. donovani remain unknown.

Trypanosomiasis due to Trypanosoma evansi, also known as 'surra' in tropical regions of the world, is generally regarded as an important disease of large ruminants and horses. It is transmitted mechanically by tabanid flies (Tabanus spp.) and Stomoxys spp.. However dogs can also become infected following consumption of the carcass of an infected animal. Trypanosomiasis occurs throughout Asia, although it appears to affect companion animals infrequently [10]. Trypanosoma evansi infection in dogs causes a severe disease, with affected individuals showing signs of malaise, fever, generalized oedema, corneal opacity, anaemia, liver enlargement and rapid progression to death. Diagnosis of canine trypanosomiasis is generally made by observation of trypomastigotes in thick or thin blood films, buffy coat smears, or in tissues by mouse inoculation. However, examination by microscopy may under-diagnose the disease because in chronic infection level of parasitemia can be very low [92]. Recently, a TaqMan PCR assay using ribosomal DNA has been develop to detect T. evansi and determine the number of organisms present in a blood sample from an infected animals [93]. The parasites have been observed in the blood of clinically normal dogs, suggesting that it does not always cause serious disease and subclinical infection can occur [10].

In a survey conducted at Ludhiana [94], 4.68\% (3/64) of dogs were found to be sub-clinically infected through examination of blood smears during the rainy season. These dogs were kept mainly in an area with a considerable population of dairy cattle. Recently, a cattle farmer was diagnosed with trypanosomiasis caused by $T$. evansi in Maharashtra, India [95]. Even though transmission of the disease in this case was speculated to originate from the cattle population, the possibility of dogs becoming another animal reservoir for human infection cannot be dismissed.

\section{Conclusion}

The information regarding CVBD in India is still far from clear. Available literatures imply that filariasis, babesiosis and ehrlichiosis are endemic throughout India, however the identity of these CVBD to a species level remain anecdotal. Despite advances in diagnosis and prophylaxis resulting from extensive research in recent years, most cases and surveys of these diseases in India were diagnosed by morphological observation only, a technique that is limited by its low sensitivity and specificity. Thus, a more comprehensive review of the prevalence of these diseases is still required. A greater understanding of these diseases encompassing both the veterinary clinical aspects and their potential public health significance is also needed in order to better inform veterinarians and pet owners about the risks, prevalence, treatment and control of CVBD. Future studies engaging molecular tools and vector investigation will hopefully help in achieving this aim.

\section{Competing interests}

The authors declare that they have no competing interests.

\section{Authors' contributions}

PAMAR was involved in intellectual content, preparation and writing the manuscript. PJI, MG, GTC and RJT were involved in intellectual input and critical revision of the manuscript for publication. All authors read and approved the final manuscript.

\section{Acknowledgements}

This work is supported by Bayer Animal Health. We are deeply thankful to Dr. Ridhhi Pednekar, Dr. Chetan Parmar and Dr. Vishwanath Jadhav, postgraduate students at Bombay Veterinary College who have helped us with local literature searches. Publication of this thematic series has been sponsored by Bayer Animal Health GmbH.

\section{Author Details}

1School of Veterinary Science, The University of Queensland, Queensland 4072, Australia, ${ }^{2}$ School of Veterinary and Biomedical Science, Murdoch University, Western Australia 6150, Australia and ${ }^{3}$ Bombay Veterinary College, Maharastra Animal and Fisheries Sciences University, Parel, Mumbai 400012, India

Received: 4 February 2010 Accepted: 8 April 2010

Published: 8 April 2010

References

1. Patz JA, Campbell-Lendrum D, Holloway T, Foley JA: Impact of regional climate change on human health. Nature 2005, 438:310-317.

2. Menezes R: Rabies in India. Can Med Assoc J 2008, 178:564

3. Sudarshan MK, Mahendra BJ, Madhusudhana SN, Ashwoath Naraya DH, Rahman A, Rao NS, X-Meslin F, Lobo D, Ravikumar K, Gangaboraiah : An epidemiological study of animal bites in India: results of a WHO sponsored national multi-centric rabies survey. J Commun Dis 2006, 38(1):32-39.

4. Irwin P, Traub R: Parasitic diseases of cats and dogs in the tropics. Perspect Agric Vet Sci Nutr Nat Resour 2006, 1:21.

5. Woodford JD: Synergies between veterinarians and para-professionals in the public and private sectors: organisational and institutional relationships that facilitate the process of privatising animal health services in developing countries [abstract]. Rev Sci Tech 2004, 23:115-135.

6. Macpherson CN, Meslin FX, Wandeler Al: Dogs, Zoonoses and Public Health Anthony Rowe Limited, Eastbourne; 2000.

7. Irwin PJ: Companion animal parasitology: a clinical perspective. Int J Parasitol 2002, 32:581-593.

8. Rishniw M, Barr SC, Simpson KW, Frongillo MF, Franz M, Dominguez Alpizar JL: Discrimination between six species of canine microfilariae by a single polymerase chain reaction. Vet Parasito/ 2006, 135:303-314.

9. Simón F, Kramer LH, Roman A, Blasini W, Morchón R, Marcos-Atxutegi C, Grandi G, Genchi C: Immunopathology of Dirofilaria immitis infection. Vet Res Commun 2007, 31:161-171.

10. Irwin PJ, Jefferies R: Arthropod-transmitted diseases of companion animals in Southeast Asia. Trends Parasitol 2004, 20:27-34.

11. Theis $\mathrm{JH}$ : Public health aspects of dirofilariasis in the United States. Vet Parasitol 2005, 133:157-180.

12. Foroulis CN, Khaldi L, Desimonas N, Kalafati G: Pulmonary dirofilariasis mimicking lung tumor with chest wall and mediastinal invasion. Thorac Cardiovasc Surg 2005, 53:173-175.

13. Moorhouse DE: Dirofilaria immitis: A cause of human intra-ocular infection. Infection 1978, 6:192-193.

14. Tada I, Sakaguchi Y, Eto K: Dirofilaria in the Abdominal Cavity of a Man in Japan. Am J Trop Med Hyg 1979, 28:988. 
15. Dobson C, Welch JS: Dirofilariasis as a cause of eosinophilic meningitis in man diagnosed by immunofluorescence and arthus hypersensitivity. Trans R Soc Trop Med Hyg 1974, 68:223-228.

16. Theis JH: Case report: Unusual location of Dirofilaria immitis in a 28year-old man necessitates orchiectomy. Am J Trop Med Hyg 2001, 64:317-322.

17. Kim MK, Kim CH, Yeom BW, Park SH, Choi SY, Choi JS: The first human case of hepatic dirofilariasis. J Korean Med Sci 2002, 17:686-690.

18. Pampiglione S, Rivasi F: Human dirofilariasis due to Dirofilaria (Nochtiella) repens: an update of world literature from 1995 to 2000. Parassitologia 2000, 42:231-254.

19. Shekhar KC, Pathmanathan R, Krishnan R: Human infection with Dirofilaria repens in Malaysia. J Helminthol 1996, 70:249-252.

20. Sabu L, Devada K, Subramanian H: Dirofilariosis in dogs \& humans in Kerala. Indian J Med Res 2005, 121:691-693.

21. Cancrini G, Romi R, Gabrielli S, Toma L, Di Paolo M, Scaramozzino P: First finding of Dirofilaria repens in a natural population of Aedes albopictus. Med Vet Entomol 2003, 17:448-451.

22. Cringoli G, Rinaldi L, Veneziano V, Capelli G: A prevalence survey and risk analysis of filariosis in dogs from the Mt. Vesuvius area of southern Italy. Vet Parasitol 2001, 102:243-252.

23. Hashem M, Badawy A: Hematological and biochemical studies on filariasis of dogs. Internet J Vet Med 2008, 4(2):

24. Huynh T, Thean J, Maini R: Dipetalonema reconditum in the human eye. BrJ Ophthalmol 2001, 85:1391

25. Nelson GS: Dipetalonema reconditum (Grassi, 1889) from the dog with a note on its development in the flea, Ctenocepkalides felis and the louse, Heterodoxus spiniger. J Helminth 1962, 36:297-308

26. Nelson GS: Dipetalonema drancunculoides (Cobbold, 1870), from the dog in Kenya: wth a note on its development in the louse-fly, Hippobosca longipennis. J Helminthol 1963, 37:235-240.

27. Gogoi AR: Filarids of animals in India. J Vet Parasitol 2002, 16:131-138

28. Ananda KJ, D'Souza PE, Jagannath MS: Methods for identification of microfilaria of Dirofilaria repens and Dipetalonema reconditum. J Vet Parasitol 2006, 20:45-47.

29. Dam T, Das P: The importance of dirofilariasis in India. Internet J Parasitic Dis 2006, 1(1):

30. Borthakur SK, Sarmah K, Rajkhowa TK, Das MR, Rahman S: Dirofilaria immitis infection in dog. J Vet Parasitol 2006, 20:167-169.

31. Patnaik MM: On filarial nematodes in domestic animals in Orissa. Indian Vet J 1989, 66:573-574.

32. Lai C-H, Tung K-C, Ooi H-K, Wang J-S: Susceptibility of mosquitoes in central Taiwan to natural infections of Dirofilaria immitis. Med Vet Entomol 2001, 15:64-67.

33. Cancrini G, Frangipane di Regalbono A, Ricci I, Tessarin C, Gabrielli S, Pietrobelli M: Aedes albopictus is a natural vector of Dirofilaria immitis in Italy. Vet Parasitol 2003, 118:195-202

34. Tiawsirisup S, Kaewthamasorn M: The potential for Aedes albopictus (Skuse) (Diptera:Culicidae) to be a competent vector for canine heartworm, Dirofilaria immitis (Leidy). Southeast Asian J Trop Med Public Health 2007, 38:208-214

35. Kumar NP, Rajavel AR, Natarajan R, Jambulingam P: DNA barcodes can distinguish species of Indian mosquitoes (Diptera: Culicidae). J Med Entomol 2009, 44:1-7.

36. Current weather forecast and climatological information - India [http:/ /www.worldweather.org/066/m066.htm

37. Galliard H, Dang Van NGU: Seasonal variations of the development of $D$. immitis in A. albopictus. Ann Parasit Humaine et Comparee 1938, 16:210-214

38. Kutz FW, Dobson RC: Effects of temperature on the development of Dirofilaria immitis (Leidy) in Anopheles quadrimaculatus Say and on vector mortality resulting from this development. Ann Entomol Soc Am 1974, 67:325-331.

39. Christensen BM, Hollander AL: Effect of temperature on vector-parasite relationships of Aedes trivittatus and Dirofilaria immitis. Proceedings of the Helminthological Society of Washington 1978, 45:115-119.

40. Frimeth JP, Hisao PA: Some potential mosquito vectors of the canine heartworm, Dirofilaria immitis, in the Calgary region of southern Alberta. Can J Zool 1982, 61:1156-1158.

41. Lai C-H, Tung K-C, Ooi H-K, Wang J-S: Competence of Aedes albopictus and Culex quinquefasciatus as vector of Dirofilaria immitis after blood meal with different microfilarial density. Vet Parasitol 2000, 90:231-237.
42. Badhe BP, Sane SY: Human pulmonary dirofilariasis in India: a case report. J Trop Med Hyg 1989, 92:425-426

43. Medlock JM, Barrass I, Kerrod E, Taylor MA, Leach S: Analysis of climatic predictions for extrinsic incubation of Dirofilaria in the United Kingdom. Vector-Borne Zoonotic Dis 2007, 7:4-14.

44. World Health Organization: Report of a Consultative Meeting, Lymphatic Filariasis Infection and Disease Control Strategies. TDR/CTD/ FIL/PENANG/1994, 1:1-2

45. World Health Organization: Bridging the Gaps. The World Health Report. Geneva: World Health Organization; 1995.

46. Orihel TC, Eberhard ML: Zoonotic Filariasis. Clin Microbiol Rev 1998, $11: 366$

47. Abdullah WO, Oothuman P, Yunus H: Detection of circulating antigens and parasite specific antibodies in filariasis. Southeast Asian J Trop Med Public Health 1993, 24:31-36.

48. Chansiri K, Tejangkura T, Kwaosak P, Sarataphan N, Phantana S, Sukhumsirichart W: PCR based method for identification of zoonostic Brugia malayi microfilariae in domestic cats. Mol Cell Probes 2002, 16:129-135

49. Regu K, Rajendran R, Ali MK, Koya SM, Dhariwal AC, Lal S: Decline of Brugian filariasis in Cherthala Taluk, Alappuzha district, Kerala. J Commun Dis 2005, 37:209-218.

50. Edeson JFB, Wilson T, Wharton RH, Laing ABG: Experimental transmission of Brugia malayi and B. pahangi to man. Trans R Soc Trop Med Hyg 1960, 54:229-232.

51. Mak JW, Yen PK, Lim KC, Ramiah N: Zoonotic implications of cats and dogs in filarial transmission in Peninsular Malaysia. Trop Geogr Med 1980, 32:259-264

52. Nuchprayoon S, Junpee A, Nithiuthai S, Chungpivat S, Suvannadabba S, Poovorawan Y: Detection of filarial parasites in domestic cats by PCRRFLP of ITS1. Vet Parasitol 2006, 140:366-372.

53. Jayewardene LG: On two filarial parasites from dogs in Ceylon, Brugia ceylonensis n. sp. and Dipetalonema sp. inq. J Helminthol 1962 36:269-280

54. Rajapakshe R, Perera WSR, Ihalamulla RL, Weerasena KH, Jayasinghe S, Sajeewani HBR, Thammitiyagodage MG, Karunaweera ND: Study of dirofilariasis in a selected area in the Western Province. Ceylon Med J 2005, 50:58

55. Dissanaike AS, Bandara CDJ, Padmini HH, Ihalamulla RL, Naotunne TDS: Recovery of a species of Brugia, probably B. ceylonensis, from the conjunctiva of a patient in Sri Lanka. Ann Trop Med Parasitol 2000, 94:83-86.

56. Lymphatic filariasis [http://www.who.int/mediacentre/factsheets/ fs102/en/

57. Human filariasis parasite found in dogs [http://www.hindu.com/2008/ 12/06/stories/2008120654580400.htm

58. Supali T, Rahmah N, Djuardi Y, Sartono E, Rückert P, Fischer P: Detection of filaria-specific lgG4 antibodies using Brugia Rapid test in individuals from an area highly endemic for Brugia timori. Acta Trop 2004, 90:255-261

59. Irwin PJ, Hutchinson GW: Clinical and pathological findings of Babesia infection in dogs. Aust Vet $J 1991,68: 204-209$.

60. Uilenberg G, Franssen FF, Perie NM, Spanjer AA: Three groups of Babesia canis distinguished and a proposal for nomenclature. Vet Q 1989, 11:33-40.

61. Zahler M, Schein E, Rinder H, Gothe R: Characteristic genotypes discriminate between Babesia canis isolates of differing vector specificity and pathogenicity to dogs. Parasitol Res 1998, 84:544-548.

62. Uilenberg G: Babesia -- A historical overview. Vet Parasitol 2006, 138:3-10.

63. Barr SC, Bowman DD: The 5-Minute Veterinary Consult Clinical Companion: Canine and Feline Infectious Diseases and Parasitology lowa, Blackwell Publishing; 2006.

64. Kjemtrup AM, Conrad PA: A review of the small canine piroplasms from California: Babesia conradae in the literature. Vet Parasitol 2006, 138:112-117.

65. Shaw SE, Day MJ, Birtles RJ, Breitschwerdt EB: Tick-borne infectious diseases of dogs. Trends Parasitol 2001, 17:74-80.

66. Stegeman JR, Birkenheuer AJ, Kruger JM, Breitschwerdt EB: Transfusionassociated Babesia gibsoni infection in a dog. J Am Vet Med Assoc 2003 222:959-963. 
67. Fukumoto S, Suzuki H, Igarashi I, Xuan X: Fatal experimental transplacental Babesia gibsoni infections in dogs. Int J Parasitol 2005 35:1031-1035.

68. Jefferies R, Ryan UM, Jardine J, Broughton DK, Robertson ID, Irwin PJ: Blood, Bull Terriers and Babesiosis: further evidence for direct transmission of Babesia gibsoni in dogs. Aust Vet J 2007, 85:459-463.

69. Sundar N, Balachandran C, Senthivelan A: Incidence of Babesia gibsoni infection in dogs in Tamil Nadu. J Vet Parasitol 2004, 18(1):79-80.

70. Chaudhuri S: Studies on clinico-therapeutic aspects of babesiosis in dogs. In MVSC Thesis Indian Veterinary Research Institute; 2006.

71. Chaudhuri S, Varshney JP: Clinical management of babesiosis in dogs with homeopathic Crotalus horridus 200C. Homeopathy 2007, 96:90-94

72. Anderson BE, Dawson JE, Jones DC, Wilson KH: Ehrlichia chaffeensis, a new species associated with human ehrlichiosis. J Clin Microbiol 1991 29:2838-2842

73. Juyal PD, Kalra IS, Singhla LD: Prevalence of haemoprotozoans in domestic animals in Punjab. 6th National congress of Veterinary Parasitology 1994

74. Samaradni D, Maske DK, Kolte SW, Shinde PN: Ehrlichiosis in dogs in Nagpur. J Vet Parasitol 2003, 17:165-166.

75. Lakshmanan B, John L, Gomathinayagam S, Dhinakarraj G: Molecular detection of Ehrlichia canis from blood of naturally infected dogs in India. Veterinarski Arhiv 2007, 77:307.

76. Baneth GAD, Samish M, Alekseev E, Aroch I, Shkap V: Transmission of Hepatozoon canis to dogs by naturally-fed or percutaneously-injected Rhipicephalus sanguineus ticks. J Parasitol 2001, 87:606-611.

77. Baneth G, Mathew JS, Shkap V, Macintire DK, Barta JR, Ewing SA: Canine hepatozoonosis: two disease syndromes caused by separate Hepatozoon spp. Trends Parasitol 2003, 19:27-31.

78. Baneth $\mathrm{G}$, Weigler B: Retrospective case-control study of hepatozoonosis in dogs in Israel. J Vet Intern Med 1997, 11:365-370.

79. Baneth GAD: Canine hepatozoonosis-Two different diseases. 29th World Small Animal Veterinary Association World Congress Proceedings; Rhodes, Greece 2004.

80. Mylonakis ME, Koutinas AF, Baneth G, Polizopoulou Z, Fytianou A: Mixed Ehrlichia canis, Hepatozoon canis, and presumptive Anaplasma phagocytophilum infection in a dog. Vet Clin Path 2004, 33:249-251.

81. Pawar SD, Gatne ML: Some haematological and biochemical profiles in canine hepatozoonosis. J Vet Parasitol 2005, 19(2):171-172.

82. Gupta MP, Nauriyal DC, Juyal PD, Kalra IS, Khahra SS, Mohan R: Therapeutic trials of Hepatozoon canis infection in dogs. Indian Vet $J$ 1994, 71:1221-1221.

83. Sharma RL, Ranga Rao GSC, Varshney JP: Parasitic diseases of canines An overview. Int J Anim Sci 1997, 12:231-244.

84. Ashford RW: Leishmaniasis reservoirs and their significance in control. Clin Dermatol 1996, 14:523-532.

85. Manual on Visceral Leishmaniasis Control [http://www.who.int leishmaniasis/surveillance/training/en/WHO LEISH 96.40.pdf]

86. Herwaldt BL: Leishmaniasis. Lancet 1999, 354:1191-1199.

87. Slappendel RJ, Ferrer L: Greene CE: Infectious Diseases of the Dog and Cat Philadelphia: WB Saunders Co; 1998:450-458

88. McConkey SE, López A, Shaw D, Calder J: Leishmanial polyarthritis in a dog. Can Vet J 2002, 43:607

89. Ahuja A, Purohit SK, Yadav JS, Netra PR: Cutaneous leishmaniasis in domestic dogs. Indian J Public Health 1993, 37:29-31.

90. Sharma V, Purohit SK, Sharma G, Joshi R, Mehta RD, Kochar DK: Cutaneous leishmaniasis in dogs and human beings in Bikaner, Rajashtan. J Vet Public Health 2003, 1:69-73.

91. Sharma N, Mahajan VK, Kanga A, Sood A, Katoch VM, Mauricio I, Singh CD, Parwan UC, Sharma VK, Sharma RC: Localized cutaneous leishmaniasis due to Leishmania donovani and Leishmania tropica: Preliminary findings of the study of 161 new cases from a new endemic focus in Himachal Pradesh, India. Am J Trop Med Hyg 2005, 72:819-824.

92. Da Silva AS, Costa MM, Wolkmer P, Zanette RA, Faccio L, Gressler LT, Dorneles TEA, Santurio JM, dos Anjos Lopes ST, Monteiro SG: Trypanosoma evansi: Hematologic changes in experimentally infected cats. Exp Parasitol 2009, 123:31-34

93. Taylor TK, Boyle DB, Bingham J: Development of a TaqMan PCR assay for the detection of Trypanosoma evansi, the agent of surra. Vet Parasitol 2008, 153:255-264.
94. Singh B, Kalra IS, Gupta MP, Nauriyal DC: Trypanosoma evansi infection in dogs: seasonal prevalence and chemotherapy. Vet Parasitol 1993, 50:137-141

95. Joshi PP, Shegokar VR, Powar RM, Herder S, Katti R, Salkar HR, Dani VS, Bhargava A, Jannin J, Truc P: Human trypanosomiasis caused by Trypanosoma evansi in India: The first case report. Am J Trop Med Hyg 2005, 73:491-495.

doi: $10.1186 / 1756-3305-3-28$

Cite this article as: Megat Abd Rani et al., Canine vector-borne diseases in India: a review of the literature and identification of existing knowledge gaps Parasites \& Vectors 2010, 3:28

\section{Submit your next manuscript to BioMed Central and take full advantage of:}

- Convenient online submission

- Thorough peer review

- No space constraints or color figure charges

- Immediate publication on acceptance

- Inclusion in PubMed, CAS, Scopus and Google Scholar

- Research which is freely available for redistribution
C BioMed Central 